\title{
POLÍTICAS DE FORMAÇÃO CONTINUADA PARA O ATENDIMENTO EDUCACIONAL ESPECIALIZADO EM QUIRINÓPOLIS-GO
}

\author{
Delvania dos Santos Freitas Silva \\ Secretaria Municipal de Educação de Quirinópolis-GO. \\ Mestre em Educação pela Universidade Federal de Uberlândia-UFU. \\ E-mail: delvaniafreitas_1@ hotmail.com
}

\begin{abstract}
RESUMO
O presente estudo é resultado parcial da pesquisa de mestrado que analisou dois cursos de formação continuada para professores de Atendimento Educacional Especializado (AEE) no Município de Quirinópolis-Go, entre os anos 2017 a 2019. "Diretrizes e Reflexão das Práticas Pedagógicas na Educação Inclusiva (2017)" e "As novas práticas pedagógicas na Perspectiva da Inclusão Escolar (2018)". Uma pesquisa bibliográfica e documental, de abordagem qualitativa, natureza básica, de objetivo exploratório, com análises de dados realizada à luz da Análise do Discurso em Foucault. Para tanto, utilizou-se entrevistas semiestruturadas, com quatro professoras de AEE de diferentes redes e contexto. Buscou-se analisar a repercussão dos cursos na percepção dos egressos quanto a prática pedagógica, bem como avaliação e indicações. Os resultados sugeriram que: a) existe uma perspectiva de controle e exceção nas práticas discursivas dos sujeitos da pesquisa, desdobramentos das orientações dos setores reguladores e orientados do Estado de Goiás; b) a existência de uma força revigorante do modelo de segregação, apesar de a legislação vigente estar enraizada em propostas de mudanças, que não ocorreram; e c) se a luta for esvaziada, os retrocessos poderão ser ainda maiores, regredindo à existência de espaços segregadores, sendo, portanto, importante a manutenção dos cursos na perspectiva de problematização e luta por uma Educação que promova a autonomia e a independência dos sujeitos, de superação da busca pela normalização das pessoas e de se estabelecer como meta diária a prática de se analisar os próprios discursos quanto à prática pedagógica no exercício da docência e valoração das diferenças.
\end{abstract}

Palavras-chave: Políticas Pública. Docência. Empoderamento.

\section{INTRODUÇÃO}

Os debates em torno da Educação Inclusiva que a partir de 1970 ganharam as ruas e os meios acadêmicos, passam novamente por momentos de incertezas. Política e democraticamente falando, são de insegurança, os objetivos são completamente distintos e a validade das pesquisas se perdem rapidamente. A afirmativa ocorre não por causa do momento agravante de pandemia (Covid 2019 ${ }^{1}$ ) e de estudo remoto, mas pelo acirramento do modelo liberal e neoliberal que foi se ampliando e os processos de

\footnotetext{
${ }^{1}$ Desde o início de fevereiro, a Organização Mundial da Saúde (OMS) passou a chamar oficialmente a doença causada pelo novo coronavírus de Covid-19. COVID significa Corona Virus Disease (Doença do Coronavírus), enquanto "19" se refere a 2019, quando os primeiros casos em Wuhan, na China, foram divulgados publicamente pelo governo chinês no final de dezembro. Disponível em:https://portal.fiocruz.br/pergunta/por-que-doenca-causada-pelo-novo-virus-recebeu-o-nome-de-covid19 Acesso em: 23 de junho de 2020.
} 
recrutamento e a concorrência para um lugar no mercado de trabalho, que por sua vez, garantia inserção no mesmo enquanto consumidor definidos a partir dos anos 1990.

A situação-problema vai além das muitas indagações, uma vez que se questiona "como" e o que se fará para efetivar a Educação como um todo? Quais serão os reais procedimentos adotados no universo da Educação Inclusiva? E como caminhará a Formação Inicial e Continuada que subsidiam a implantação das novas diretrizes? Enfim, o debate e as mobilizações precisam ser acentuados para que as políticas não recuem ou caiam no esquecimento. São momentos de crise, de transição, improbabilidades, mas acima de tudo, de orientação e luta incansável.

A realidade nacional demonstra avanços, no entanto, ainda há muito que ser pensado e construído para que todos os estudantes ingressem na escola e aprendam. Para tanto, há necessidade de que os sistemas de ensino invistam na formação continuada de seus profissionais.

Nesse sentido, o objetivo geral se definiu, por analisara repercussão dos cursos na percepção dos egressos quanto a prática pedagógica, bem como que avaliação e indicações faziam sobre os dois cursos "Diretrizes e Reflexão das Práticas Pedagógicas na Educação Inclusiva (2017)" e “As novas práticas pedagógicas na Perspectiva da Inclusão Escolar (2018)", em relação ao AEE das escolas públicas no município de Quirinópolis-Go.

Justifica-se a necessidade de pensar a complexidade dos discursos e das relações que são criadas em torno do AEE nas escolas públicas, e que podem contribuir para que as políticas públicas não se efetivem plenamente, quer seja, pela ação das pessoas que estão diretamente nas escolas, quer seja, pela conjuntura do sistema. Fischer (2001, p. 198), ao analisar a construção discursiva do social em Foucault afirma "que é preciso trabalhar arduamente com o próprio discurso, deixando-o aparecer na complexidade que lhe é peculiar".

Conjuntura que não pode ser analisada desassociada do contexto histórico, cultural, político, econômico e cultural. Da mesma forma, as variantes Educação Especial/Inclusiva, com suas políticas educacionais, ao salientar aquelas de formação de professores da Educação Básica para atuação no AEE.

Em suma, a pesquisa em todo seu conteúdo buscou analisar, subsidiar, caracterizar e ampliar a compreensão sobre as Políticas Públicas de AEE e de Formação Continuada na perspectiva da Educação Inclusiva ultimada no lócus município de 
Quirinópolis; saber como o professor percebe as políticas de formação de professores de AEE e os conceitos aprendidos nos cursos de formação que a compõem em sua prática, ou seja, as implicações como apontamentos e tomadas de atitudes no AEE, reconhecendo os desafios, mas primordialmente refletindo e contextualizando estas experiências na contraversão realidade versus prática.

\section{POLÍTICAS DE FORMAÇÃO CONTINUADA DE PROFESSORES DO AEE EM QUIRINÓPOLIS-GO}

Quirinópolis é um município brasileiro do Estado de Goiás, localizada no sudoeste Goiano e à microrregião homônima. Distante da capital Goiânia, cerca de 290 $\mathrm{km}$, com população estimada de 53 mil habitantes e ocupa uma área de $3.780 \mathrm{~km}^{2}$ (IBGE, 2010).

Atualmente, (2020), o município conta com 36 estabelecimentos de ensino, sendo sete escolas estaduais, destas, uma é de tempo integral e outra que oferece Educação de Jovens e Adultos (EJA) e Educação Prisional; nove escolas municipais de Ensino Fundamental primeira e segunda fase, sendo duas militarizadas e uma de Educação de Jovens e Adultos (EJA) noturna; cinco Centros Municipais de Educação Infantil (CEMEI), quatro escolas rurais polos e todas conveniadas com o Estado oferecendo o Ensino Médio; três escolas particulares; duas do sistema Sesi Senai e Senac; uma Cooperativa de Ensino de Quirinópolis (CEQ); uma conveniada do Lions Clube, o Centro de Atendimento Educacional Especializado (CAEE) que atende pessoas com deficiência de todas as redes e alguns matriculados apenas no centro, e cinco IES com a UEG.

Quanto ao AEE, até bem recente, o único espaço, em Quirinópolis, que o ofertava estava localizado no Centro de Atendimento Educacional Especializado (CAEE). A partir de 2011 passou a ser viabilizado em outras escolas da rede municipal, chegando a oito escolas com espaços e atendimentos na rede municipal. Em 2018, foi aberta uma sala em um colégio da rede estadual.

Das oito escolas que possuem AEE, optou-se por entrevistar cursistas de instituições com características diferenciadas, visando perceber as implicações e percepções dos mesmos, conforme o espaço de aplicação do conteúdo aprendidos nos cursos, ou seja, professoras das Escolas Municipal Rural Polo Adélia de Freitas, 
Municipal D. Pedro I (urbana), Colégio Estadual Neida Ferreira e do Centro de Atendimento Educacional Especializado (CAEE) Dr. Alfredo Mariz da Costa. ${ }^{2}$

Ressalta-se que todas as escolas reconhecidas pelo MEC, a partir de 2008, receberam os materiais necessários à implantação das salas multifuncionais, no entanto, até 2011 nenhuma das doze escolas existentes possuía o AEE. Todo este atendimento era deslocado para o CAEE, antiga Escola Especial, cujo caráter dos centros se mantêm ocupando-se do cuidado especial e não da Educação Especial. A legislação prioriza que a oferta ocorra na própria escola para não criar dificuldades para os estudantes usufruírem do seu direito com mais tranquilidade e menos desgastes familiares. Realidade essa que, muda novamente em Goiás, a partir das Diretrizes 2020-2022, em que o CAEE passa-se novamente a ser Escolas Especiais de Educação Básica.

Quanto aos cursos de formação continuada oferecidos pela SME da cidade registra-se que somente a partir de 2006 iniciaram os cursos pré-implantação da Educação na Perspectiva Inclusiva. Outra disparidade notada, foi que, conforme os cursos alvo da pesquisa foram sendo ministrados percebeu-se as múltiplas percepções dos profissionais quanto ao formato e constituição do AEE e as formas de atendimento.

Os registros históricos quanto à Educação Especial no Município de Quirinópolis se confundem com a trajetória da Escola Especial Dr. Alfredo Mariz da Costa, fundada em 1981, pela Fundação Lions Clube de Quirinópolis, onde permanece até os dias atuais. No município se encarregou de conduzir os encaminhamentos, momentos históricos e as políticas públicas dos períodos de segregação, integração e inclusão. Em 31 de outubro de 2008 que o Conselho Estadual de Educação de Goiás credenciou a escola por tempo indeterminado a atos pedagógicos e lhe entregou o Decreto $\mathrm{n}^{\circ} 6.571$ de 17 de setembro de $2008^{3}$, que dispunha sobre o AEE.

No entanto, a não existência de políticas públicas de obrigatoriedade, mas com a opção de preferencialmente do funcionamento das Salas de Recursos fez com que as ações do governo se perdessem. Até o início do ano de 2017 nas escolas do município, apenas, duas Escolas, Maria Ignez e Raio de Sol, possuíam salas de AEE em

\footnotetext{
${ }^{2}$ Nomes fictícios para preservar a identidade das instituições e das entrevistadas, apenas o CAEE, que por ser única no atendimento especial no município, se manterá com o nome real, contudo, preservado o anonimato da professora de AEE, uma vez que a instituição possui mais de uma sala e outros profissionais que desenvolvem esse trabalho).

${ }^{3}$ Registra-se que o Decreto $\mathrm{n}^{\circ} 6.571$ de 17 de setembro de 2008, foi posteriormente revogado e regulamentado pelo de $\mathrm{N}^{\mathrm{0}}$ 7.611, de 17 de novembro de 2011. Que dispõe sobre a educação especial, o Atendimento Educacional Especializado e dá outras providências.
} 
funcionamento, o número se ampliou para cinco escolas em 2018 e oito em 2019, somadas ao CAEE e a Escola Neida Ferreira totalizavam dez escolas.

A princípio deveria haver um trabalho colaborativo pela Escola Especial, quer seja, nos cursos de formação continuada, ou nas parcerias com as salas de aula comuns, estas escaparam a partir do momento que foram criadas salas de AEE dentro dos CAEEs. Afirma Teixeira (2014, p. 15) que "embora as atividades do AEE se diferenciem das realizadas em salas de aula, o professor deverá promover ampla articulação entre tais atividades com a finalidade de alcançar a melhoria da qualidade da formação dos alunos se de suas capacidades”.

Condição pensada a partir das políticas de formação de professores da Educação Básica para atuação no AEE, na perspectiva inclusiva que começaram a ser elaboradas na década de 1990, pelo Ministério da Educação, cumprindo agenda e resoluções da Conferencia Mundial de Educação para Todos, culminando nos Estados e municípios no Plano Decenal (1993-2003). Nos interiores do Estado de Goiás, iniciaram por volta de 1995, conduzidas pela Secretaria de Educação, Cultura e Desporto, sob a responsabilidade da Superintendência do Ensino Especial (SEE), com sua divisão de apoio administrativo e sede na capital Goiânia.

A partir da LDB de 1996, contextualiza-se nos cursos de formação continuada as atualizações, ou complementação da carreira, e, para tanto, constitui-se as redes, com o objetivo primordial de consolidar a proposta mundial de educação para o mercado trabalhista. Nesse sentido, a formação preconizada inovadora implica ao professor ser aquele que media competências, suas e de seus alunos, que aceita que é preciso sempre aprender, que viva uma totalidade harmônica e ética e que saiba utilizar as tecnologias; discurso da lógica do mercado.

Qualquer semelhança com os momentos atuais, não traduz coincidência, elucida procedimentos que permitem o controle dos discursos. Foucault (2014, p. 34) adverte que "[...] ninguém entrará na ordem do discurso se não satisfizer a certas exigências ou se não for, de início, qualificado para fazê-lo".

Porém, e, contrapondo às ressalvas, Foucault (2014, p. 36) adverte que “[...] a troca e a comunicação são figuras positivas que atuam no interior de sistemas complexos de restrição; e sem dúvida não poderiam funcionar sem estes”. É assim, que Foucault sugere a necessidade de reconhecer as "grandes fendas" na apropriação social dos discursos, compreendendo que “[...] todo sistema de educação é uma maneira 
política de manter ou de modificar a apropriação dos discursos, com os saberes e os poderes que eles trazem consigo" (FOUCAULT, 2014, 41).

Os cursos analisados pela pesquisa tem proclamado a necessidade de autonomia docente, no sentido de aprender a aprender, de empoderamento, e, observou que esta somente acontece a partir do conhecimento construído na articulação entre teoria e prática. E, assim, compreender que "o discurso não é simplesmente aquilo que traduz as lutas ou os sistemas de dominação, mas aquilo porque, pelo que se luta e o poder do qual nós queremos apoderar" (FOUCAULT, 2014, p. 10).

Ressalta-se aqui os dois cursos, objeto da pesquisa, que nasceram de um diagnóstico realizado entre os próprios docentes, quanto à realidade das salas de AEE e os módulos caminharam conduzidos por profissionais lotados na secretaria, convidados e por cursistas que dominavam os assuntos.

O primeiro (2017), dividido em dez módulos, totalizou quarenta horas (40), "Diretrizes e Reflexão das Práticas Pedagógicas na Educação Inclusiva", trouxe na apresentação do seu projeto o conceito de a inclusão, como "um processo complexo que abrange diferentes dimensões, sejam ideológicas, socioculturais, políticas e econômicas" (SOUZA, 2017, p. 4).

Os conteúdos foram escolhidos com o objetivo de dotar os profissionais de fundamentação teórica, capaz de articular teoria e prática pedagógica com capacidade de análise crítica, de forma a minimizar os obstáculos do ensino e da aprendizagem, ou seja, na perspectiva de oferecer autonomia aos professores. O resultado, especialmente das oficinas, em grupo, foi publicado pelos cursistas no Seminário de Ensino Pesquisa e Extensão (SEPE) da Universidade Estadual de Goiás, Campus Quirinópolis e, posteriormente, registrado por Silva e Souza (2018, p. 22-43) em um capítulo do livro Vozes da Educação.

A finalização desse curso, inspirou a elaboração do projeto de “As novas práticas pedagógicas na Perspectiva da Inclusão Escolar (2018)”, com carga horária de 120 horas e o sonho da finalização com um livro que pudesse implicar em novas percepções/concepções e práticas dos cursistas egressos.

Da mesma forma, esse curso também foi organizado e coordenado pela equipe de coordenação da Educação Inclusiva da Secretaria, formação continuada direcionada a professores de AEE, e de apoio das Escolas municipais de Quirinópolis. Com os mesmos objetivos do curso de 2017, mas com o diferencial da ampliação de conteúdos e 
a participação efetiva dos professores de AEE nos temas trabalhados, sendo que alguns participaram ora como cursista, ora como palestrante. Foi dividido em doze módulos, mais atividades complementares de orientação para escrita do capítulo de livro (optativa).

Após o estudo das especificidades foi montado grupos de apresentação em que, cada equipe deveria se aprofundar mais sobre o tema, buscando conhecer mais sobre o histórico, conceitos, políticas públicas, materiais pedagógicos que já vinham sendo utilizados nas salas de AEE e/ou implementados durante o curso e a finalização com a exposição teórica e prática do estudo. Ao final todos os grupos expuseram, compartilhando o aprendizado na forma de seminário e troca de experiência. Esses temas se tornaram os capítulos de um livro organizados pela coordenação e pela pesquisadora.

Experiência gratificante, principalmente porque não era obrigatória a participação na escrita do livro, pois poder-se-ia optar por um relatório final, conjugava parte complementar do curso, mas dos oitenta inscritos houve participação ativa de cinquenta um cursistas. A orientação para a pesquisa e escrita ficou a cargo das organizadoras, se reuniam disciplinarmente toda quarta feira na UEG/NUPED, fato que agregou excelentes resultados ao curso.

\section{CONSIDERAÇÕES FINAIS}

Sendo verificado que não existe política específica de formação continuada no município e que os cursos em sua maioria são emergenciais, o que mostra a preocupação de alguns gestores, mas por não se tratar de políticas de Estado se perdem muito rápido com as mudanças de governo, porém, a partir de 2006 foram mais intensos e que estes cursos, têm sim, contribuído para modificar a prática, senão de todos educadores, pelo menos dos professores de AEE que passaram a perceber a escola inclusiva como um nexo de redes que vão além do seu trabalho em sala de aula.

A perspectiva do AEE era se ser espaço de mobilização, de formação e ganho de autonomia dentro da escola regular, mas, se deparou com a falta de formação pedagógica e compromisso político de seus mobilizadores na escola, falta de robustez das políticas públicas, que servem mais para subordiná-la, que incluí-la, mantendo a ação disciplinar da escola, o que não permitiu avanços e alavancou retrocessos, como o 
retorno dos estudantes da Educação Especial para os centros de atendimentos segregatícios.

Nesse aspecto, a tendência crescente de fortalecimento de princípios relacionados ao liberalismo, são as perdas de diretos coletivos, tanto trabalhistas, quanto das minorias étnicos, religiosos, de gênero, dos grupos de pessoas com deficiência. Resta ser resistência, não perder de vista as linhas de fuga e, cautelosamente, permitirse outros modos de existência frente à vida, não dando destaque ao jeito de ser diferente, mas nas diferentes formas de ser diferente.

O cenário previsto, que se desenha para a educação especial observada nas diretrizes de 2020, em Goiás, que se propõe Centros de Educação Básica e Especial e nos enfrentamentos das políticas de mercado em tempo de pandemia se apontam, ainda, mais sombrias, o que justifica a fala inicial de Foucault (2014, p. 25) "o novo não está no que é dito, mas no acontecimento de sua volta", pois vai exigir mais de quem percebe a inclusão como prática de si e do outro.

A pesquisa em si, apontou que existe uma perspectiva de controle e exceção; uma força revigorante do modelo de segregação; que a legislação vigente estão enraizadas em propostas de mudanças que não ocorreram e ficaram mais no imaginário do professor de AEE, do que no real da escola, que deveria ser inclusiva, porém, se a luta for esvaziada os retrocessos poderão ser ainda maiores. E, finalmente, a relevância de continuar promovendo cursos de formação na perspectiva de problematização e luta por uma educação que gere autonomia dos sujeitos.

A percepção constatada, nesta pesquisa, assegura que a inclusão é necessária, desde que não seja para normalização do sujeito, mas como meta diária de se analisar os próprios discursos quanto a prática pedagógica e à docência, pois o elemento de realidade que se tem, precisa ser e estar constantemente em análise. E, assim, seguir acreditando que, "não existem lugares com certa concentração de poder enquanto outros lugares seriam como um vácuo sem poder", conforme registrou Diniz e Oliveira (20132014, p. 147) ao conceituar em Foucault (1979) o poder.

A pesquisa, sem ter a pretensão de ser absoluta avança no sentido de se construir novas reflexões e abordagens quanto a cautela no cuidado com o próprio discurso, pois ao acaso ele pode servir para esvaziar a luta pela inclusão. É preciso, pois, acreditar que nas práticas sociais, onde quer se esteja, aí estará a função de existência. 


\section{REFERÊNCIAS}

BRASIL. Decreto $\mathbf{N}^{\mathbf{0}} \mathbf{6 . 5 7 1}$, de 17 de setembro de 2008. Ministério da Educação. Secretaria de Educação Especial. DOU de 18 set. 2008.

Plano decenal de educação para todos. - Brasília: MEC, 1993 - versão acrescida 136 p. 1. Política da educação 2. Planejamento da educação 3. Educação básica 4. MEC. Secretaria de Educação Fundamental I. Brasil. Ministério da Educação e do Desporto. Disponível em http://livros01.livrosgratis.com.br/me002599.pdf Acesso em: 20 de dezembro de 2018.

Lei $\mathbf{N}^{\circ} 9394$ de 20 de dezembro de 1996. Estabelece as diretrizes e bases da

Educação Nacional. [1996], 2017. Disponível em: http://www.planalto.gov.br/ccivil_03/leis/L9394.htm. Acesso em: 20 jan. 2019.

DINIZ, Francisco Rômulo Alves; OLIVEIRA, Almeida Alves de Oliveira. Foucault: do poder disciplinar ao biopoder. In: Scientia, Vila Velha-ES, v. 2, n. 3 - Nov. 2013/Jun. 2014.

FISCHER, Rosa Maria Bueno. Foucault e a análise do discurso em educação. In: Caderno de Pesquisa, São Paulo, n. 114, p. 197-223, Nov. 2001.

FOUCAULT [1926-1984]. A ordem do discurso: aula inaugural no Collége de France, pronunciada em 2 de dezembro de 1970. Trad. Laura Fraga de Almeida Sampaio. 24. ed. São Paulo: Edições Loyola, 2014.

IBGE - Instituto Brasileiro de Geografia e Estatística. Pesquisa Nacional por Amostra de Domicílios: síntese de indicadores 2010. Rio de Janeiro: IBGE. IBGE - Instituto Brasileiro de Geografia e Estatística, 2010.

INEP. Instituto Nacional de Estudos e Pesquisas Educacionais Anísio Teixeira. INEP. Plano Nacional de Educação PNE 2014-2024: Linha de Base. - Brasília, DF: Inep, 2015. Disponível em: http://www.publicacoes.inep.gov.br/portal/download/1362 Acesso em: 01 de outubro de 2019.

Instituto Nacional de Estudos e Pesquisas Educacionais Anísio Teixeira (INEP).

Censo Escolar, 2019. Brasília: INEP/MEC, 2019. Disponível em: http://portal.inep.gov.br/web/guest/resultados-e-resumos Acesso em: 10 de junho de 2020. Acesso em junho de 2020.

GOIÁS. Diretrizes Operacionais da Rede Pública Estadual de Goiás 2020-2022. Goiânia-Go, 2020. SEDUC/GO. https://site.educacao.go.gov.br/wpcontent/uploads/2020/02/Diretrizes_Operacionais_Rede_Publica_Estadual_de_Educaca o_de_Goias_2020_2022.pdf. Acesso em 04 de abril de 2020.

TEIXEIRA, Geovana Ferreira Melo. Formação de professores para o atendimento educacional especializado: uma necessidade, um direito. In. SILVA, Lázara Cristina da; MOURÃO, Marisa Pinheiro; SILVA, Wender Faleiro da. Orgs. Atendimento 
educacional para surdos: tons e cores da educação continuada de professores no exercício profissional. Uberlândia: EDUFU, 2014.

SOUZA, Sandra Augusta de Lima Souza. Projeto de Formação Continuada. Diretrizes e Reflexão das Práticas Pedagógicas na Educação Inclusiva. SME/CME. Quirinópolis-Go, 2017.

SILVA, Delvania dos Santos Freitas; SOUZA, Sandra Augusta de Lima. Atendimento Educacional Especializado (AEE): Formação continuada como requisito para a educação Inclusiva na Rede Pública Municipal de Quirinópolis-Go. In: DICKMANN, Ivanio. (Org.) Vozes da Educação: uma partilha de educadores e educadoras que refletem sobre suas vivências cotidianas em diferentes espaços pedagógicos. Volume II. São Paulo-SP: Dialogar, 2018. p. 22-43.

SILVA, Delvania dos Santos Freitas. Políticas de formação continuada de professores do Atendimento Educacional Especializado (AEE) em QuirinópolisGO - 2017/2019. 2020. 186 f. Dissertação (Mestrado em Educação) - Universidade Federal de Uberlândia, Uberlândia, 2020. 